\title{
BMJ Open Depressive symptoms, life satisfaction and prevalence of sleep disturbances in the general population of Germany: results from the Heinz Nixdorf Recall study
}

\author{
Maria Elena Lacruz, ${ }^{1}$ Andrea Schmidt-Pokrzywniak, ${ }^{1}$ Nico Dragano, ${ }^{2}$ \\ Susanne Moebus, ${ }^{3}$ Susanne Eva Deutrich, ${ }^{1}$ Stefan Möhlenkamp, ${ }^{4}$ \\ Axel Schmermund, ${ }^{5}$ Hagen Kaelsch, ${ }^{6}$ Raimund Erbel, ${ }^{6}$ Andreas Stang ${ }^{3,7}$
}

To cite: Lacruz ME, SchmidtPokrzywniak A, Dragano N, et al. Depressive symptoms, life satisfaction and prevalence of sleep disturbances in the general population of Germany: results from the Heinz Nixdorf Recall study. BMJ Open 2016;6:e007919. doi:10.1136/bmjopen-2015007919

- Prepublication history and additional material is available. To view please visit the journal (http://dx.doi.org/ 10.1136/bmjopen-2015007919).

Received 11 February 2015 Revised 27 October 2015 Accepted 29 October 2015

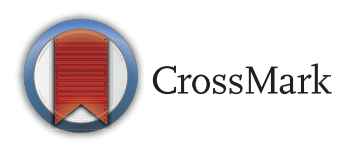

For numbered affiliations see end of article.

Correspondence to Dr Maria E Lacruz; elena.lacruz@uk-halle.de

\section{ABSTRACT}

Objectives: It appears that not only depression, but also low life satisfaction (LS), is related to sleep disorder in the general population. We evaluate whether the prevalence of sleep disorder attributable to depressed mood is greater among participants with Iow LS.

Setting, participants and outcome measures: Analysis of cross-sectional data from 3880 cohort members from the German Heinz Nixdorf Recall study (2006-2008) aged 51-81 years. Standard mood (Center for Epidemiological Studies Depression scale (CES-D) for Depressive symptoms and a single-item life satisfaction measure) and sleep quality (Pittsburgh Sleep Quality Index, PSQI) measures were conducted as part of the survey. Multiple imputation was used to deal with missing data in outcome, exposures or covariates. Relative excess risk for interaction (RERI) and its 95\% Cls were estimated using adjusted prevalence ORs. Owing to the study size, the precision of the measures of additive interaction is relatively low.

Results: We observed an association between depressed mood (5-units increase in CES-D score) (POR=1.7 (95\% Cl 1.6 to 1.8)) and sleep disorder, and between low LS (not very satisfied vs very satisfied) (POR=1.5 (1.1 to 2.2)) and sleep disorder. Also, we observed a synergistic effect between lower level of LS (not very satisfied) and depressed mood (score $\geq 16$ ) on prevalence of sleep disorders $(\mathrm{RER})=3.7(-0.2$ to 7.1)). Furthermore, these findings were corroborated in sensitivity analysis carried out with the complete case data set and in sex-specific analyses (RERI=5.5 (-0.4 to 11.3 ), and $R E R I=2.4$ ( -2.5 to 7.4 ) for men and women, respectively).

Conclusions: Both depressed mood and LS are notably associated with sleep quality, and these relationships are best captured by considering their joint effects. Depression and LS need to be taken into consideration when analysing sleep quality.

\section{Strengths and limitations of this study}

- This study draws strength from its size and from the fact that it is a population-based sample, with well-defined health outcomes and inclusion of an exhaustive list of relevant covariates.

- This study examines the relationship between mood and sleep quality considering the joint effects of both stable and unstable aspects of mood.

- Our sample consisted of adults in a restricted age range (51-81 years) and, as with any crosssectional design, the directionality of the observed associations cannot be determined. The precision of our measures of additive interaction (RERI) was quite low because of the sample size.

\section{INTRODUCTION}

Sleep is an important source of general health and well-being. ${ }^{1}$ Sleep disturbances have been associated with health problems, including poor self-rated health, psychological conditions, chronic medical conditions and mortality. ${ }^{2}$ The prevalence of sleep disturbances in the population is dependent on its definition, and it ranges from $6 \%$ (clinical diagnosis of insomnia) to $48 \%$ (difficulties in initiating or maintaining sleep or early morning awakening). ${ }^{3}$ Considering its high prevalence and association with health conditions, there is a need to investigate the factors associated with sleep disturbance in order to develop strategies to prevent or delay its onset.

Depressive symptomatology is an affective disorder in which the prevailing emotional mood of a person is negatively distorted or inappropriate to the circumstances, and is sustained over a particular period of time. ${ }^{4}$ 
Depressive symptoms are considered an important risk factor for insomnia and, conversely, sleep disturbances are very common $(60-80 \%$ prevalence $)$ among depressed patients. ${ }^{2}$ In patients with depressive symptoms, insomnia appears either previously $(40 \%)$ or simultaneously (22\%) with other psychological, physical and social symptoms. ${ }^{5}$ Following the International Classification of Disease, 10th revision (ICD-X) definition, sleep disturbances are very clearly a symptom of depression and do not precede it. However, sleep disorder are a predictor for depressive relapse if they are a residual symptom after remission. ${ }^{6}$ Though, a recent meta-analysis has shown that sleep disturbances can also lead to depression. ${ }^{7}$ Also, in a recent systematic review of nine cohort studies (8 longitudinal and 1 retrospective), the available evidence suggested that sleep disturbances and depression were bidirectionally associated. ${ }^{8}$

Life satisfaction (LS), is a component of subjective well-being. ${ }^{6}$ It refers to cognitive judgments that remain quite constant even over a longer period of time. ${ }^{9}{ }^{10} \mathrm{~A}$ review revealed that subjective well-being, and not only the absence of mental illness, has an effect on all-cause morbidity and mortality. ${ }^{11}$ In addition, LS is related to health predictors such as favourable self-reported health, social support and positive health behaviours. ${ }^{12}$ Several studies have shown moderate correlations between LS and depressive symptoms, and support independency, indicating that research on indicators of wellbeing adds a distinctive dimension to psychiatric research. ${ }^{13}$

While there are numerous studies associating depression with poor sleep quality (for a review see ref. 14), there have been fewer studies evaluating associations of well-being and sleep quality. Cross-sectional studies have shown that lower well-being is associated with lower sleep quality. ${ }^{15-17}$ Additionally, these associations appear to be independent of psychological stressors. ${ }^{18}$ Therefore it appears that, in the general population, not only depression, but also well-being is associated with sleep quality. Previous research has shown that depressive symptoms, a transitional period of low mood (state), are associated with worse sleep quality. ${ }^{19}$ However, whether well-being, which tends to be stable over time (trait), can alter that association, has not yet been investigated. Recent research has shown that the relationship between mood and sleep quality is best captured by considering the joint effects of both stable and unstable aspects of mood. ${ }^{17}$

There is some support for the assumption that different levels of LS might differentially affect the association between depressive symptomatology and sleep quality. Several studies have shown that resilience, the ability to prosper despite stress and adversity, is associated with LS, ${ }^{20} 21$ or that it can even foster LS. ${ }^{22}{ }^{23}$ Moreover, resilience has been associated with better health outcomes in the face of stress and adversity. ${ }^{24}{ }^{25}$ Therefore, it can be assumed that, for participants with higher LS (thus more resilient), depressive symptomatology would have weaker effects on their sleep quality; whereas for participants with lower LS (and thus less resilient), small levels of depressive symptomatology could lead to greater sleep disturbances.

\section{Aims}

This study focuses on the association between depressive symptoms and sleep disturbances, and whether this association can be modified by LS. The study aims to extend our understanding of the relationship between depressive symptoms and the presence of sleep disturbances. In particular, using cross-sectional data from the Heinz Nixdorf Recall Study (2006-2008), we assessed the presence of an interaction between depression and LS on sleep quality, by studying whether the joint effect of exposure to both factors was greater than the sum of their independent effects. We hypothesised that: (1) depressive symptoms would negatively relate to sleep quality; (2) LS would be positively associated with sleep quality and (3) LS would modulate the relation between depressive symptoms and sleep quality. While an explanation of this link cannot be advanced in the frame of a cross-sectional study, it nevertheless seems justifiable to examine the hypothesis that LS modifies this association, such that stronger associations of depressive symptoms with sleep quality are observed among adults with lower LS.

\section{MATERIALS AND METHODS}

\section{Study population and study sample}

Data were derived from the Heinz Nixdorf Recall (Risk Factors, Evaluation of Coronary Calcium and Lifestyle) Study: a cross-sectional analysis of participants in the follow-up survey when sleep quality and mood assessments took place. The design of the study has been previously described in detail. ${ }^{26}$ Briefly, during the baseline examination between December 2000 and August 2003, a total of 4814 participants, aged between 45 and 75 years, were recruited from three adjacent cities in the German Ruhr Area: Essen, Bochum, Mülheim/ Ruhr. ${ }^{26} 27$ The baseline recruitment proportion was $56 \%{ }^{28}$ All participants were invited for re-examination in 2006-2008. Overall, 154 of 4814 participants (3\%) died before re-examination and 503 refused examination $(10 \%)$, leading to a final 5-year follow-up group of 4157 participants $(87 \%)$. Data collection at follow-up was carried out through standardised interviews, clinical examination, comprehensive laboratory tests and selfadministered questionnaires. An internal and external quality management system was established according to industrial standard norms DIN ISO 9001:2000/2008. All participants gave written informed consent.

\section{Outcome}

Sleep quality and sleep disturbances over the preceding month were measured through the Pittsburgh Sleep Quality Index (PSQI). ${ }^{29}$ In this index, the 19 self-rated 
items are combined to form 7 component scores, each of which has a range of $0-3$ points. A score of ' 0 ' indicates no difficulty, while a score of ' 3 ' indicates severe difficulties. The 7 component scores are then added to yield a 'global' score, with a range of 0-21 points, ' 0 ' indicating no difficulty and '21' indicating severe sleep disturbances. For the purposes of our study, we examined the PSQI global score, which was calculated using the algorithm outlined in Buysse et al, ${ }^{29}$ where a PSQI global score greater than 5 was classified as poor quality sleep.

\section{Major exposures}

Depressive symptoms over the preceding week were assessed by self-administered questionnaire through the 15 items Center for Epidemiologic Studies Depression scale (CES-D 15). ${ }^{30} 31$ We modified the CES-D scale by excluding the symptom 'my sleep was restless' to remove the item's correlation with questions on sleep disturbances. ${ }^{32}$ Thus, the scale had 14 items and a score range of $0-42$, with higher scores indicative of more symptomatology. A cut-off of 18 has been suggested for depressive symptom screening in the German population..$^{33}$ Owing to the removal of an item, we considered various cut-offs for depressive symptoms (16 and 18).

LS was measured by a self-administered questionnaire through the following question: 'how satisfied are you with your personal life?' Answer categories were: very satisfied; usually satisfied; unsatisfied. ${ }^{34}$ The item-total correlation of this question with the items of the Satisfaction With Life Scale (SWLS) has been reported to be $0.75 .{ }^{36}$ Additionally, recent studies have shown that similar single-item LS measures showed a good criterion validity with the SWLS ( $\mathrm{r}=0.62) .{ }^{37}$ For analysis purposes, we dichotomised this item in 'very satisfied' versus 'not very satisfied', because only $6 \%$ of the population was categorised as 'unsatisfied'. There were no differences in sex distribution, alcohol consumption, body mass index (BMI), cholesterol level, hypertension status or education level among participants in each LS category. However, unsatisfied participants were younger, more often suffered from depressed mood, sleep disturbances and life events, had lower SNI, were more often current smokers and were physically inactive. In our sample, the association between the dichotomous LS and the CES-D score with logistic regression analysis was only moderate $(\mathrm{OR}=0.9$, CI 0.8 to 0.9 in a crude model and $\mathrm{OR}=0.8$, CI 0.8 to 0.8 in an age and sex-adjusted model).

\section{Covariates}

Covariates known to affect sleep quality (outcome) that were also associated with either depressive symptoms or LS (exposures of interest) were identified from the literature $^{14-18}$ and discussed prior to the analyses. Sociodemographic variables: age, sex and socioeconomic status, were obtained at baseline. Education was used as a proxy for socioeconomic status, classified in years of formal education according to the
'International Standard Classification of Education' combining school and vocational training. Four categories were defined with the highest category of 18 and more years of education (equivalent to a University degree), category 3 with 14-17 years, category 2 with 1113 years and the lowest category of 10 and fewer years (equivalent to a basic school degree and no vocational training). Anthropometric measurements (weight and height, BMI $\mathrm{kg} / \mathrm{m}^{2}$ ) and blood pressure, were determined at the clinical examination. Lifestyle factors were determined through personal interview (alcohol consumption and smoking habits). Social support, physical activity and life events were determined in the standardised interview. Social support was characterised using the Berkman-Syme's Social Network Index. ${ }^{38}$ The components of the index are weighted in an algorithm resulting in four categories (I: low, II: mid-low, III: mid-high, IV: high). Physical activity was assessed by asking participants about the types and duration of exercises performed in the preceding month, whereby 'physically inactive' meant having performed no exercise at all. ${ }^{39}$ In the self-administered questionnaire, participants were asked to report whether any stressful life events had occurred in the past 6 months, to which they could answer yes or no. Self-rated health was assessed in the interview by one question ('How would you, referring to the past 12 months, describe your overall health status?'), on a 5-point Likert-scale ('very good', 'good', 'moderate', 'poor' and 'very poor').

\section{Statistical methods}

The present study includes only the 3880 participants at follow-up ( $89 \%$ of the follow-up participants) who filled in the questionnaire. We identified minimally sufficient adjustment sets using diagrams that represent the relations among the exposure, outcome and other variables. ${ }^{40}$ All previously mentioned covariates were considered potential adjustment variables for the relation of LS and depressive symptoms with sleep quality. The minimally sufficient adjustment set for the association of LS and sleep quality included age, sex, socioeconomic status, smoking, BMI, alcohol consumption, cholesterol, modified CES-D, social support, life events and physical activity. The minimally sufficient adjustment set for the association of depressive symptoms and sleep quality included age, sex, socioeconomic status, smoking, BMI, alcohol consumption, cholesterol, LS, social support, life events and physical activity.

We used multivariable logistic regression to estimate PORs (prevalence OR) that account for depressive symptoms and LS on sleep quality. Exposures were analysed dichotomously (CES-D score $\geq 16$ vs $<16$ and $\mathrm{LS}=$ very satisfied vs not very satisfied) and continuously (depressive symptoms per 5 unit increase, previously reported as clinically relevant) or categorically (LS three categories). ${ }^{41}$ Seven hundred twenty-two of $3880(19 \%)$ participants had missing data for sleep quality, depressive symptoms, LS or covariates. To manage missing data 
we undertook multiple imputation, using the MI procedure in SAS. We generated an imputed database containing 20 imputed versions using all relevant variables predicting missingness (PSQI score, LS, CES-D score, age, alcohol consumption, BMI, blood pressure, cholesterol level, life events, sport index score, sex, smoking status, SNI and education level). Regression results were combined using the MIANALYZE procedure in SAS. We explored the pattern of missing data and performed sensitivity analyses on complete cases. Furthermore, we studied the presence of interaction (relative excess risk due to interaction (RERI)) between depressive symptoms and LS by comparing the joint effects of exposure to both factors with the sum of their independent effects. The estimated RERI was calculated as follows: ${ }^{42}$

$$
\mathrm{RERI}=\mathrm{OR}_{11}-\mathrm{OR}_{10}-\mathrm{OR}_{01}+1
$$

where $\mathrm{OR}_{11}$ denotes $\mathrm{OR}$ among those exposed to both factors (depressive symptom aetology and low LS). A RERI of 0 means no interaction, a RERI $>1$ means interaction without monotonicity assumption for one exposure and a RERI $>2$ means interaction even without monotonicity assumption for both exposures. ${ }^{42}{ }^{43} \mathrm{We}$ performed several sensitivity analyses with the complete case data set $(\mathrm{N}=3158)$. In the first sensitivity analysis, we assumed that both depressive symptoms and sleep quality are strongly sex-dependent, therefore we did sexstratified interaction analysis to investigate sex-specific patterns. In the second analysis, a higher cut-off for the depression scale (CES-D) was chosen, in order to investigate the robustness of our results. In a third analysis, exposures were treated as continuous (depressive symptoms) or categorical (LS) variables. We have calculated and reported CIs to assess the precision of our estimates because our goal is the estimation and not significance testing. We wish to avoid publication bias by preferential reporting of significant results. Instead, we judge the value of our estimates by their precision and validity. All analyses were performed using SAS V.9.3 (SAS Inc, Cary, North Carolina, USA).

\section{RESULTS}

\section{Sample characteristics}

A total of 1932 participants (50\%) were classified in the 'good sleep quality' group, which consisted of $57 \%$ men with a mean age of 64.4 years (SD 7.5, 51-81 years). A total of 1477 participants (38\%) were classified in the 'sleep disturbances' category, which was $38 \%$ male with a mean age of 65.3 years (SD 7.6). A further 471 participants $(12 \%)$ did not answer the PSQI questionnaire. Table 1 shows demographic and clinical characteristics of participants stratified by sleep quality. Most clinical risk factors (age, hypertension, BMI, cholesterol and physical activity) were not different between the index population of 'good sleep quality' and the 'sleep disturbed' subgroup. On the contrary, most sociodemographic and psychological variables, for example, educational level, self-rated health, social network index, life events, depressive symptoms and LS, showed different prevalence rates between subgroups. Additionally, participants in the good sleep quality group were more often men, more often current or former smokers and more often consumed alcohol.

\section{Association of depressive symptoms and LS with sleep quality}

Table 2 presents the POR estimates for sleep quality with depressive symptoms as a continuous variable (data are shown per 5 unit increments in CES-D scale) and LS as a categorical variable. Similar results were obtained with complete case analysis and multiple imputation, thus we report effect estimates from the multiple imputation analyses. For 'depressive symptoms', there was a strong association between depressive symptoms (higher scores in CES-D; 5-units increment) and sleep disturbances ( $\mathrm{POR}=1.7,95 \%$ CI 1.6 to 1.8 ). The results of the logistic regression indicate that participants reporting lower LS (unsatisfied) had an increased prevalence of suffering from sleep disturbances compared with participants reporting higher LS (very satisfied) ( $\mathrm{POR}=1.5,95 \% \mathrm{CI}$ 1.1 to 2.2). The results of the logistic regression with depression and LS dichotomised are presented in online supplementary table S1. The results indicate that participants with higher CES-D scores (depressive symptoms; scores $\geq 16$ ) had an increased prevalence of suffering from sleep disturbances than non-depressed participants ( $\mathrm{POR}=4.8,95 \%$ CI 3.6 to 5.4). Participants reporting lower LS had an increased prevalence of suffering from sleep disturbances compared with participants reporting higher $\mathrm{LS}(\mathrm{POR}=1.6,95 \%$ CI 1.3 to 1.8$)$.

\section{Interaction between LS and depressive symptoms on the prevalence of sleep disturbances}

The combined effects of depressive symptoms and LS on sleep quality were greater than the sums of the separate estimated effects (table 3 and online supplementary table S2). Multiple imputation and complete case analysis yielded very similar results, thus we reported results from imputed data. The RERI for depressive symptoms (score $\geq 16$ in the CES-D scale) and LS was 3.7 (95\% CI -0.2 to 7.1 ), which indicates that, because of the interaction between depressive symptoms and LS, the POR is 3.7 times higher than expected from the addition of the separate effects of depressive symptoms and LS alone. Results for complete case analysis were comparable and are presented in online supplementary table S2.

\section{Sensitivity analysis}

Several sensitivity analyses in the complete case data set were performed. Sex-stratified interaction analysis produced similar results (RERI=2.4 $(-2.5$ to 7.4$)$ and RERI=5.5 (-0.4 to 11.3) for women and men 
Table 1 Demographic and clinical characteristics of participants stratified by sleep quality

\begin{tabular}{|c|c|c|c|}
\hline Variable & Total & $\begin{array}{l}\text { Sleep quality } \\
\text { Good }{ }^{\star} \\
(\mathrm{N}=1932)\end{array}$ & $\begin{array}{l}\text { Poort } \\
(\mathrm{N}=1477)\end{array}$ \\
\hline \multicolumn{4}{|l|}{ Sex } \\
\hline Women: $\mathrm{n}(\%, \mathrm{Cl})$ & 1746 & $823(42.6: 40.4$ to 44.8$)$ & $923(62.5: 60.0$ to 65.0$)$ \\
\hline Men: $\mathrm{n}(\%, \mathrm{Cl})$ & 1663 & 1109 (57.4:55.2 to 59.6$)$ & $554(37.5: 35.0$ to 40.0$)$ \\
\hline \multicolumn{4}{|l|}{ Education } \\
\hline <10 years: $\mathrm{n}(\%, \mathrm{Cl})$ & 324 & $140(7.3: 6.1$ to 8.4$)$ & $184(12.5: 10.8$ to 14.1$)$ \\
\hline $11-13$ years: $n(\%, C l)$ & 1910 & 1005 (52.0:49.8 to 54.2) & 905 (61.3:58.8 to 63.8$)$ \\
\hline $14-17$ years: $n(\%, C l)$ & 791 & $531(27.5: 25.5$ to 29.5$)$ & $260(17.6: 15.7$ to 19.5$)$ \\
\hline$\geq 18$ years: $n(\%, C l)$ & 384 & 256 (13.3:11.7 to 14.8$)$ & $128(8.7: 7.2$ to 10.1$)$ \\
\hline \multicolumn{4}{|l|}{ Smoking } \\
\hline Never smoker: $\mathrm{n}(\%, \mathrm{Cl})$ & 1392 & 731 (39.0:36.7 to 41.2$)$ & $661(46.7: 44.1$ to 49.3$)$ \\
\hline Former smoker: $\mathrm{n}(\%, \mathrm{Cl})$ & 1343 & 809 (43.1:40.9 to 45.3$)$ & 534 (37.7:35.2 to 40.2$)$ \\
\hline Current smoker: $\mathrm{n}(\%, \mathrm{Cl})$ & 558 & $337(18.0: 16.2$ to 19.7$)$ & $221(15.6: 13.7$ to 17.5$)$ \\
\hline \multicolumn{4}{|l|}{ Self-rated health } \\
\hline Very good: $n(\%, \mathrm{Cl})$ & 164 & $137(7.3: 6.1$ to 8.5$)$ & $27(1.9: 1.2$ to 2.6$)$ \\
\hline Good: $n(\%, \mathrm{Cl})$ & 1314 & $922(49.2: 46.9$ to 51.4$)$ & $392(27.7: 25.4$ to 30.0$)$ \\
\hline Fair: $n(\%, \mathrm{Cl})$ & 1275 & 645 (34.4:32.2 to 36.5$)$ & $630(44.5: 41.9$ to 47.1$)$ \\
\hline Poor: n (\%, Cl) & 446 & $137(7.3: 6.1$ to 8.5$)$ & 309 (21.8:19.7 to 24.0$)$ \\
\hline Very poor: n (\%, Cl) & 93 & 35 (1.9:1.3 to 2.5$)$ & $58(4.1: 3.1$ to 5.1$)$ \\
\hline \multicolumn{4}{|l|}{ Social network index } \\
\hline I (low): n (\%, Cl) & 856 & $443(23.7: 21.8$ to 25.6$)$ & $413(29.2: 26.8$ to 31.6$)$ \\
\hline II: n (\%, Cl) & 1254 & 715 (38.2:36.0 to 40.4$)$ & 539 (38.1:35.6 to 40.7$)$ \\
\hline III: n (\%, CI) & 942 & 567 (30.3:28.2 to 32.4$)$ & $375(26.5: 24.2$ to 28.8$)$ \\
\hline IV (high): n (\%, Cl) & 232 & $145(7.8: 6.5$ to 9.0$)$ & $87(6.2: 4.9$ to 7.4$)$ \\
\hline \multicolumn{4}{|l|}{ Hypertension $\ddagger$} \\
\hline Yes: n (\%, Cl) & 1250 & 755 (40.4:38.2 to 42.6$)$ & $495(35.1: 32.6$ to 37.6$)$ \\
\hline \multicolumn{4}{|l|}{ Physical activity } \\
\hline Active: $n(\%, C l)$ & 1504 & $816(43.5: 41.2$ to 45.7$)$ & $688(48.6: 46.0$ to 51.2$)$ \\
\hline \multicolumn{4}{|l|}{ Life events in past 6 months } \\
\hline Yes: $\mathrm{n}(\%, \mathrm{Cl})$ & 695 & $346(18.2: 16.5$ to 20.0$)$ & 349 (24.1:21.9 to 26.3$)$ \\
\hline \multicolumn{4}{|l|}{ Depressed mood (CES-D $\geq 16) \S$} \\
\hline Yes: n (\%, Cl) & 294 & $58(3.1: 2.3$ to 3.8$)$ & 236 (16.3:14.4 to 18.3$)$ \\
\hline \multicolumn{4}{|l|}{ Life satisfaction } \\
\hline Very satisfied: $n(\%, C l)$ & 1194 & $778(41.2: 39.0$ to 43.4$)$ & $416(28.9: 26.5$ to 31.2$)$ \\
\hline Quite satisfied: $n(\%, \mathrm{Cl})$ & 1943 & $1045(55.4: 53.1$ to 57.6$)$ & $898(62.3: 59.8$ to 64.8$)$ \\
\hline Unsatisfied: $\mathrm{n}(\%, \mathrm{Cl})$ & 192 & $65(3.4: 2.6$ to 4.3$)$ & 127 (8.8:7.3 to 10.3$)$ \\
\hline Depressed mood: mean (SD)§ & 3338 & $5.3(4.4)$ & $9.5(6.7)$ \\
\hline Age years: mean (SD) & 3409 & $64.4(7.5)$ & $65.3(7.6)$ \\
\hline BMI $\left(\mathrm{kg} / \mathrm{m}^{2}\right)$ : mean (SD) & 3287 & $28.1(4.6)$ & $28.3(5.1)$ \\
\hline Total cholesterol mg/dL: median (Q1;Q3) & 3274 & $226(199 ; 254)$ & $223(199 ; 249)$ \\
\hline HDL cholesterol mg/dL: median (Q1;Q3) & 3274 & $59(49 ; 71)$ & $57(48 ; 69)$ \\
\hline Alcohol consumption mL/week: mean (SD) & 3306 & $70.2(102.7)$ & $57.8(107.6)$ \\
\hline \multicolumn{4}{|c|}{$\begin{array}{l}\text { Data are presented as } n(\%) \text { unless otherwise stated. } \\
\text { *Good sleep quality: PSQI score } \leq 5 \text {. } \\
\text { †Poor sleep quality: PSQI score }>5 \text {. } \\
\text { †Participants on antihypertensive medication or with systolic blood pressure } \geq 140 \mathrm{~mm} \mathrm{Hg} \text { or diastolic blood pressure } \geq 90 \mathrm{~mm} \text { Hg were } \\
\text { defined as hypertensive. } \\
\text { §CES-D scale excludes the item 'my sleep was restless'. } \\
\text { BMI, body mass index; CES-D, Centre for Epidemiological Studies depression scale; HDL, high-density lipoprotein; PSQI, Pittsburgh Sleep } \\
\text { Quality Index. }\end{array}$} \\
\hline
\end{tabular}

respectively; see online supplementary tables S3 and S4), but have to be interpreted with caution due to the small numbers of participants in some of the categories. The additive interaction obtained with a higher cut-off for the CES-D scale (scores $\geq 18)$ was RERI $=4.2(95 \%$ CI -1.9 to 10.4$)$. We repeated the interaction analysis with depressive symptoms considered continuously (CES-D score $0-42$, per 5-unit increase) and LS in three categories. The results of this logistic regression indicate that participants with higher CES-D scores (score 15-20) had an increased prevalence of suffering from sleep disturbances than participants with lower scores (score 0-5; $\mathrm{POR}=1.9$; 95\% CI 1.6 to 2.3). Participants more dissatisfied with life ('not very satisfied') had an increased 
Table 2 Association of depressed mood and life satisfaction with sleep quality

\begin{tabular}{|c|c|c|c|c|c|}
\hline \multirow[b]{2}{*}{ Model } & \multirow[b]{2}{*}{ Adjusted for: } & \multicolumn{2}{|c|}{ Complete case analysis } & \multicolumn{2}{|c|}{ Multiple imputation } \\
\hline & & $\overline{\mathbf{N}}$ & POR (95\% Cl) & $\overline{\mathbf{N}}$ & POR (95\% Cl) \\
\hline \multicolumn{6}{|c|}{ Depressed mood (score 0-42; unit increment=5) } \\
\hline 1 & - & 3338 & $2.0(1.8$ to 2.1$)$ & 3880 & $1.8(1.7$ to 1.9$)$ \\
\hline 2 & Age and sex & 3338 & $1.9(1.8$ to 2.1$)$ & 3880 & $1.8(1.6$ to 1.9$)$ \\
\hline 3 & Fully adjusted* & 3163 & 1.8 (1.7 to 2.0$)$ & 3880 & $1.7(1.6$ to 1.8$)$ \\
\hline \multicolumn{6}{|c|}{ Life satisfaction (very satisfied, quite satisfied, unsatisfied) } \\
\hline \multirow[t]{3}{*}{1} & - & 3329 & & 3880 & \\
\hline & Very vs unsatisfied & & 3.7 (2.6 to 5.0$)$ & & $3.6(2.6$ to 4.9$)$ \\
\hline & Quite vs unsatisfied & & $2.3(1.7$ to 3.1$)$ & & $2.3(1.7$ to 3.1$)$ \\
\hline \multirow[t]{3}{*}{2} & Age and sex & 3329 & & 3880 & \\
\hline & Very vs unsatisfied & & 4.2 (3.0 to 5.8$)$ & & 4.2 (3.0 to 5.7$)$ \\
\hline & Quite vs unsatisfied & & 2.4 (1.7 to 3.2$)$ & & 2.4 (1.7 to 3.3$)$ \\
\hline \multirow[t]{3}{*}{3} & Fully adjusted $†$ & 3163 & & 3880 & \\
\hline & Very vs unsatisfied & & 1.5 (1.0 to 2.2$)$ & & 1.5 (1.1 to 2.2$)$ \\
\hline & Quite vs unsatisfied & & $1.2(0.9$ to 1.8$)$ & & $1.3(0.9$ to 1.8$)$ \\
\hline
\end{tabular}

PORs per 5 unit increment in CES-D scale (depressed mood).

*Fully adjusted: age, sex, alcohol consumption, BMI (body mass index), blood pressure, total cholesterol, life satisfaction, life events, physical activity, education years, smoking and social support.

†Fully adjusted: age, sex, alcohol consumption, BMI (body mass index), blood pressure, total cholesterol, CES-D score, life events, physical activity, education years, smoking and social support.

CES-D, Centre for Epidemiological Studies depression scale; POR, prevalence OR.

prevalence of suffering from sleep disturbances compared with participants satisfied with life ('very satisfied') ( $\mathrm{POR}=1.5$; $95 \%$ CI 0.6 to 3.9). Moreover, the RERI for depressive symptoms and LS (assessed by comparing 'very satisfied' with 'not very satisfied' and a CES-D score of 0 to a score of 16$)$ was $5.4(95 \%$ CI -10.0 to 20.8 ; data not shown).

\section{DISCUSSION}

Findings from the current study showed that both depressive symptoms and LS were notably associated with sleep quality, emphasising the importance of stable and of dynamic features of mood on sleep patterns. In agreement with previous studies, we found a negative

Table 3 Interaction between LS and depressed mood on the prevalence of sleep problems (multiple imputation, $\mathrm{N}=3880$ )

\begin{tabular}{|c|c|c|}
\hline & \multicolumn{2}{|l|}{ Life satisfaction } \\
\hline & $\begin{array}{l}\text { very satisfied } \\
\text { POR }(95 \% \mathrm{Cl})\end{array}$ & $\begin{array}{l}\text { not very } \\
\text { satisfied } \\
\text { POR }(95 \% \mathrm{Cl})\end{array}$ \\
\hline $\begin{array}{l}\text { Non-depressed mood } \\
\text { (cut-off }<16 \text { ) }\end{array}$ & 1.0 & 1.5 (1.3 to 1.8$)$ \\
\hline $\begin{array}{l}\text { Depressed mood } \\
\text { (cut-off } \geq 16 \text { ) }\end{array}$ & 3.4 (1.5 to 7.9$)$ & 7.4 (3.5 to 11.3$)$ \\
\hline \multicolumn{3}{|c|}{$\begin{array}{l}\text { Measure of interaction on additive scale: RERI }(95 \% \mathrm{Cl})=3.7 \\
(-0.2 \text { to } 7.1) \text {. } \\
\text { PORs are adjusted for age, sex, socioeconomic status, smoking, } \\
\text { BMI, alcohol consumption, cholesterol, social support, life events } \\
\text { and physical activity. } \\
\text { BMI, body mass index; POR, prevalence OR; RERI, Relative } \\
\text { excess risk for interaction. }\end{array}$} \\
\hline
\end{tabular}

relation between sleep and depressive symptoms, ${ }^{14}$ and an overall positive relation between good sleep quality and LS. ${ }^{15-18}$ Furthermore, our results suggested that these relationships were best captured by considering the joint effects of depressive symptoms and LS, with higher depressive symptoms associated with substantially worse sleep quality, especially among individuals with lower LS.

Depressive symptoms and LS were only moderately inversely related in our population. This confirms the previous literature reporting that they are distinct constructs. ${ }^{13}{ }^{44}$ Sleep disturbances are part of the diagnostic criteria for depression in ICD-10 and Diagnostic and Statistical Manual-IV; therefore it is not surprising that CES-D and PSQI scores are so strongly associated. A number of previous studies have shown that depressive symptoms are related to poorer sleep in the adult population, with OR of 1.5-3.0 in most studies. ${ }^{2}{ }^{45}$ Our results showed a higher POR for depressive symptoms (4.8, 95\% CI 3.6 to 6.5 ), probably due to the relatively high cut-off chosen in this study. Additionally, the OR for LS was similar to those previously reported, between 1.8 and $2.1(\mathrm{POR}=1.6,95 \%$ CI 1.3 to 1.8$) \cdot{ }^{46} 47$ Although, in concordance with those findings, the present results extend them in several important ways. Most notably, our study examined interaction effects of LS and depressive symptoms on sleep quality.

Ong et $a l^{17}$ examined a similar interaction, however, only on a multiplicative scale, where they showed that well-being interacts with negative reactivity on overall sleep quality. These results were expanded on the additive scale in our study. The additive interaction analysis examined whether the relative detriment of depressive symptoms on sleep quality was the same across LS 
groups. We found that participants with depressive symptoms had much worse sleep quality if they belonged to the non-satisfied group than if they belonged to the satisfied group (multiplicative interaction $\mathrm{POR}=1.5$, 95\% CI 0.6 to 3.6 ). However, from a public health perspective, additive interaction is relevant, as it can help determine which subgroups would benefit most from a given treatment, that is, psychotherapy to improve depressive symptoms and thus sleep quality in those participants with low LS. The additive interaction (RERI $=3.7,95 \%$ CI -0.2 to 7.1 ) indicates that there is a synergistic effect between depressive symptoms and LS, which substantially increased the prevalence of worse sleep quality. Our study suggests that the depressive symptoms-sleep quality association was modified by LS level in additive interaction analyses.

This study draws its strength from the size, and from the fact that it is a population-based sample with welldefined health outcomes and inclusion of an exhaustive list of relevant covariates. Nevertheless, our conclusions are limited by several factors. Our sample consisted of adults with a restricted age range (51-81 years) and, as with any cross-sectional design, the directionality of the observed associations cannot be determined. Given the age range of the study participants, it is possible that our results cannot be generalised to the complete age range of adults. Women in the postmenopausal period suffer from sleep disturbances, depressive symptoms and/or pain more often than younger and older women. Also, men in this age range more often present pain symptoms. Regarding the representability of this study population, it has been previously reported that high social class and good health status were over-represented at baseline in the Heinz Nixdorf Recall Study. ${ }^{28}$ Moreover, we used a modified version of the CES-D scale to measure depressive symptoms. Owing to this modification, we could not consider previously validated cut-offs for our population. Therefore, we ran sensitivity analyses with various cut-offs (16 and 18) in order to identify relevant changes. In the present study, we did not use sex-specific cut-offs to detect depressive symptoms, as previously described in the literature. ${ }^{48}$ However, it has been recently reported that several depression tests (Beck Depression Inventory-II, Inventory of Depressive Symptoms-self-report, and the Montgomery-Asberg Depression Rating Scale) should use different cut-offs for men and for women, to better discriminate between depressed and non-depressed participants. Yet, they also affirm that it is too early to recommend gender specific reference values for those tests and that previous studies have found no sex differences for depression scales. ${ }^{49}$ Our assessment of LS with a single-item question was limited; however, a recent study has shown that singleitem LS measures performed very similarly compared to the multiple-item SWLS, a more psychometrically established measure. ${ }^{37}$ Also, outcome and predictors (sleep quality, depressive symptoms and LS) have been analysed as dichotomous variables, though they were documented as continuous. Nevertheless, we ran sensitivity analyses with continuous (depressive symptoms) and categorical (LS) exposure variables in complete case analysis in order to identify relevant changes. Finally, the RECALL study was not powered for this research question; therefore some estimates are very imprecise.

These results extend the study of depressive symptoms, LS and sleep quality, and suggest that the association between depressive symptoms and sleep quality is modified by LS. Understanding the predictors of poor sleep quality may have important implications for future health outcomes, such as development of chronic medical conditions.

\section{Author affiliations}

${ }^{1}$ Medical Faculty, Martin-Luther-University, Institute of Medical Epidemiology, Biostatistics and Informatics, Halle, Germany

${ }^{2}$ Medical Faculty, Heinrich-Heine-University Düsseldorf, Institute for Medical Sociology, University Düsseldorf, Duesseldorf, Germany

${ }^{3}$ Institute of Medical Informatics, Biometry and Epidemiology, University Duisburg-Essen, Essen, Germany

${ }^{4}$ Medical Clinic II, Moers, Germany

${ }^{5}$ Cardioangiological Center Bethanien, Frankfurt/Main, Germany

${ }^{6}$ Department of Cardiology, West-German Heart Center Essen, University

Duisburg-Essen, Essen, Germany

${ }^{7}$ Department of Epidemiology, School of Public Health, Boston University, Boston, USA

Acknowledgements The authors are indebted to all the study participants as well as to the dedicated personnel at the study centre of the Heinz Nixdorf Recall study, the EBT-scanner facilities (Professor D Grönemeyer, Professor R Seibel) and the investigative group, in particular to U Roggenbuck, $U$ Slomiany, EM Beck, A Öffner, S Münkel, S Schrader, R Peter and H Hirche. The authors thank K Lauterbach (Harvard School of Public Health, Boston, USA) for his valuable contributions in an earlier phase of the study. The authors thank K Kröger (Krefeld) for his input into the assessment of peripheral arterial disease.

Contributors AS-P, ND, SM, SED, SM, AS, HK, RE and AS contributed to the study design and data acquisition. AS supervised all aspects of the study's execution. MEL planned the analysis and undertook the primary analysis and wrote the first draft of the paper. All the authors critically reviewed the paper and approved the submitted version.

Funding Heinz Nixdorf Foundation; Bundesministerium für Bildung und Forschung; Deutsches Zentrum für Luft- und Raumfahrt.

Competing interests This work was supported by the Heinz Nixdorf Foundation, Germany (Chairman: Martin Nixdorf, past chairman: Dr Jur G Schmidt), the German Ministry of Education and Science (BMBF) and the German Aerospace Centre (Deutsches Zentrum für Luft- und Raumfahrt (DLR)), Bonn, Germany. Assessment of psychosocial factors was funded by the German Research Council (DFG) (Project SI 236/8-1 and SI 236/9-1). Sarstedt AG \&Co (Nümbrecht, Germany) supplied laboratory equipment.

Patient consent Obtained.

Ethics approval Institutional local ethics committee.

Provenance and peer review Not commissioned; externally peer reviewed.

Data sharing statement No additional data are available.

Open Access This is an Open Access article distributed in accordance with the Creative Commons Attribution Non Commercial (CC BY-NC 4.0) license, which permits others to distribute, remix, adapt, build upon this work noncommercially, and license their derivative works on different terms, provided the original work is properly cited and the use is non-commercial. See: http:// creativecommons.org/licenses/by-nc/4.0/ 


\section{REFERENCES}

1. Endeshaw Y. Aging, subjective sleep quality, and health status: the global picture. Sleep 2012;35:1035-6.

2. Ford DE, Kamerow DB. Epidemiologic study of sleep disturbances and psychiatric disorders. An opportunity for prevention? JAMA 1989;262:1479-84.

3. Ohayon MM. Epidemiology of insomnia: what we know and what we still need to learn. Sleep Med Rev 2002;6:97-111.

4. Zung WW. From art to science. The diagnosis and treatment of depression. Arch Gen Psychiatry 1973;29:328-37.

5. Ohayon MM, Roth T. Place of chronic insomnia in the course of depressive and anxiety disorders. J Psychiatr Res 2003;37:9-15

6. Schimmack U, Radhakrishnan P, Oishi S, et al. Culture, personality, and subjective well-being: integrating process models of life satisfaction. J Pers Soc Psychol 2002;82:582-93.

7. Baglioni C, Battagliese G, Feige B, et al. Insomnia as a predictor of depression: a meta-analytic evaluation of longitudinal epidemiological studies. J Affect Disord 2011;135:10-19.

8. Alvaro PK, Roberts RM, Harris JK. A systematic review assessing bidirectionality between sleep disturbances, anxiety, and depression. Sleep 2013;36:1059-68.

9. Lyubomirsky S, King L, Diener E. The benefits of frequent positive affect: does happiness lead to success? Psychol Bull 2005;131:803-55

10. Pressman SD, Cohen S. Does positive affect influence health? Psychol Bull 2005;131:925-71.

11. Chida Y, Steptoe A. Positive psychological well-being and mortality: a quantitative review of prospective observational studies. Psychosom Med 2008;70:741-56.

12. Koivumaa-Honkanen $\mathrm{H}$, Honkanen $\mathrm{R}$, Viinamaki $\mathrm{H}$, et al. Self-reported life satisfaction and 20-year mortality in healthy Finnish adults. Am J Epidemiol 2000;152:983-91.

13. Knutson B, Wolkowitz OM, Cole SW, et al. Selective alteration of personality and social behavior by serotonergic intervention. Am J Psychiatry 1998;155:373-9.

14. Ford DE, Cooper-Patrick L. Sleep disturbances and mood disorders: an epidemiologic perspective. Depress Anxiety 2001;14:3-6.

15. Strine TW, Chapman DP, Balluz LS, et al. The associations between life satisfaction and health-related quality of life, chronic illness, and health behaviors among U.S. community-dwelling adults. $J$ Community Health 2008;33:40-50.

16. Ohayon MM, Zulley J, Guilleminault C, et al. How age and daytime activities are related to insomnia in the general population: consequences for older people. J Am Geriatr Soc 2001;49:360-6.

17. Ong AD, Exner-Cortens D, Riffin C, et al. Linking stable and dynamic features of positive affect to sleep. Ann Behav Med 2013;46:52-61.

18. Steptoe A, O'Donnell K, Marmot M, et al. Positive affect, psychological well-being, and good sleep. J Psychosom Res 2008;64:409-15

19. Armitage R. Sleep and circadian rhythms in mood disorders. Acta Psychiatr Scand Supp/ 2007;(433):104-15.

20. Cohn MA, Fredrickson BL, Brown SL, et al. Happiness unpacked: positive emotions increase life satisfaction by building resilience. Emotion 2009;9:361-8.

21. Mak WW, Ng IS, Wong CC. Resilience: enhancing well-being through the positive cognitive triad. J Couns Psychol 2011:58:610-17.

22. Gable SL, Haidt J. What (and why) is positive psychology? Rev Gen Psychol 2005;9:103-10.

23. Chida Y, Hamer M. Chronic psychosocial factors and acute physiological responses to laboratory-induced stress in healthy populations: a quantitative review of 30 years of investigations. Psychol Bull 2008;134:829-85.

24. Connor KM, Davidson JR. Development of a new resilience scale: the Connor-Davidson Resilience Scale (CD-RISC). Depress Anxiety 2003;18:76-82.

25. Bonanno GA. Loss, trauma, and human resilience: have we underestimated the human capacity to thrive after extremely aversive events? Am Psychol 2004;59:20-8.

26. Schmermund A, M öhlenkamp S, Stang A, et al. Assessment of clinically silent atherosclerotic disease and established and novel risk factors for predicting myocardial infarction and cardiac death in healthy middle-aged subjects: rationale and design of the Heinz Nixdorf RECALL Study. Risk factors, evaluation of coronary calcium and lifestyle. Am Heart J 2002;144:212-18.

27. Erbel R, Möhlenkamp S, Moebus S, et al. Coronary risk stratification, discrimination, and reclassification improvement based on quantification of subclinical coronary atherosclerosis: the Heinz Nixdorf Recall study. J Am Coll Cardiol 2010;56:1397-406.

28. Stang A, Moebus S, Dragano N, et al. Baseline recruitment and analyses of nonresponse of the Heinz Nixdorf Recall Study: identifiability of phone numbers as the major determinant of response. Eur J Epidemiol 2005;20:489-96.

29. Buysse DJ, Reynolds CF III, Monk TH, et al. The Pittsburgh Sleep Quality Index: a new instrument for psychiatric practice and research. Psychiatry Res 1989;28:193-213.

30. Radloff LS. The CES-D scale: a self-report depression scale for research in the general population. Appl Psychol Meas 1977;1:385-401.

31. Denollet J, Sys SU, Stroobant N, et al. Personality as independent predictor of long-term mortality in patients with coronary heart disease. Lancet 1996;347:417-21.

32. Foley DJ, Monjan A, Simonsick EM, et al. Incidence and remission of insomnia among elderly adults: an epidemiologic study of 6,800 persons over three years. Sleep 1999;22(Suppl 2):S366-S72.

33. Lehr AH, Schmitz AE, Sosnowsky N. [Assessing depressive disorders using the Center for Epidemiologic Studies-Depression Scale (CES-D) and State-Trait Depression Scales (STDS-T): a comparative analysis of cut-off scores]. Diagnostica 2008;54:61-70.

34. Bellach BM, Knopf H, Thefeld W. [The German Health Survey. 1997/ 98]. Gesundheitswesen 1998;60(Suppl 2):S59-68.

35. Ellert U, Knopf $\mathrm{H}$. [Satisfaction with living conditions and health]. Gesundheitswesen 1999;61:S145-S50.

36. Diener E, Emmons RA, Larsen RJ, et al. The satisfaction with life scale. J Pers Assess 1985;49:71-5.

37. Cheung F, Lucas RE. Assessing the validity of single-item life satisfaction measures: results from three large samples. Qual Life Res 2014;23:2809-18.

38. Berkman LF, Syme SL. Social networks, host resistance, and mortality: a nine-year follow-up study of Alameda County residents. Am J Epidemiol 1979;109:186-204.

39. Weyers S, Dragano N, Möbus S, et al. Poor social relations and adverse health behaviour: stronger associations in low socioeconomic groups? Int J Public Health 2010;55:17-23.

40. Greenland S, Pearl J, Robins JM. Causal diagrams for epidemiologic research. Epidemiology 1999;10:37-48.

41. Dozeman E, van Marwijk HW, van Schaik DJ, et al. High incidence of clinically relevant depressive symptoms in vulnerable persons of 75 years or older living in the community. Aging Ment Health 2010;14:828-33.

42. Knol MJ, VanderWeele TJ, Groenwold RH, et al. Estimating measures of interaction on an additive scale for preventive exposures. Eur J Epidemiol 2011;26:433-8.

43. VanderWeele TJ, Robins JM. The identification of synergism in the sufficient-component-cause framework. Epidemiology 2007;18:329-39.

44. Nes RB, Czajkowski NO, Røysamb E, et al. Major depression and life satisfaction: a population-based twin study. J Affect Disord 2013;144:51-8.

45. Paudel M, Taylor BC, Ancoli-Israel S, et al. Sleep disturbances and risk of depression in older men. Sleep 2013;36:1033-40.

46. Ohayon MM, Zulley J. Correlates of global sleep dissatisfaction in the German population. Sleep 2001;24:780-7.

47. Paunio T, Korhonen T, Hublin C, et al. Longitudinal study on poor sleep and life dissatisfaction in a nationwide cohort of twins. Am J Epidemiol 2009;169:206-13.

48. Schulte-van Maaren YW, Carlier IV, Zitman FG, et al. Reference values for major depression questionnaires: the Leiden Routine Outcome Monitoring Study. J Affect Disord 2013;149: 342-9.

49. Rush AJ, Gullion CM, Basco MR, et al. The Inventory of Depressive Symptomatology (IDS): psychometric properties. Psychol Med 1996;26:477-86. 